\title{
Teaching Ethics and Professionalism: A National Survey of Ophthalmology Residency Program Directors
}

\author{
Alyssa M. Kretz, BA ${ }^{1}$ Jennifer E. deSante-Bertkau, MD, MBE ${ }^{2}$ Michael V. Boland, MD, $\mathrm{PhD}^{3}$ \\ Xinxing Guo, MD, $\mathrm{PhD}^{4}$ Megan E. Collins, MD, $\mathrm{MPH}^{4,5}$ \\ ${ }_{1}^{1}$ Johns Hopkins University School of Medicine, Baltimore, Maryland \\ 2 Department of Pediatrics, Cincinnati Children's Hospital Medical \\ Center, University of Cincinnati College of Medicine, \\ Cincinnati, Ohio \\ ${ }^{3}$ Wilmer Eye Institute, Johns Hopkins University School of Medicine, \\ Baltimore, Maryland \\ ${ }^{4}$ Dana Center for Preventive Ophthalmology at the Wilmer Eye \\ Institute, Johns Hopkins University School of Medicine, \\ Baltimore, Maryland \\ ${ }^{5}$ Berman Institute of Bioethics, Johns Hopkins University, \\ Baltimore, Maryland \\ J Acad Ophthalmol 2021;13:e82-e88. \\ Address for correspondence Megan E. Collins, MD, MPH, Krieger \\ Children's Eye Center, Wilmer Eye Institute, 600 North Wolfe Street, \\ Wilmer 233, Baltimore, MD 21287 (e-mail: mcolli36@jhmi.edu).
}

\begin{abstract}
Keywords

- ethics

- professionalism

- graduate medical education

Background While ethics and professionalism are important components of graduate medical education, there is limited data about how ethics and professionalism curricula are taught or assessed in ophthalmology residency programs.

Objective This study aimed to determine how U.S. ophthalmology residency programs teach and assess ethics and professionalism and explore trainee preparedness in these areas.

Methods Directors from accredited U.S. ophthalmology residency programs completed an online survey about components of programs' ethics and professionalism teaching curricula, strategies for assessing competence, and trainee preparedness in these areas.

Results Directors from 55 of 116 programs (46\%) responded. The most common ethics and professionalism topics taught were informed consent (38/49, 78\%) and risk management and litigation $(38 / 49,78 \%)$, respectively; most programs assessed trainee competence via 360-degree global evaluation (36/48, 75\%). While most $(46 / 48,95 \%)$ respondents reported that their trainees were well or very well prepared at the time of graduation, 15 of $48(31 \%)$ had prohibited a trainee from graduating or required remediation prior to graduation due to unethical or unprofessional conduct. Nearly every program $(37 / 48,98 \%)$ thought that it was very important to dedicate curricular time to teaching ethics and professionalism. Overall, 16 of 48 respondents (33\%) felt that the time spent teaching these topics was too little.
\end{abstract}

received

July 13,2020

accepted after revision

December 15, 2020
DOI https://doi.org/ $10.1055 / \mathrm{s}-0040-1722741$. ISSN 2475-4757.

\footnotetext{
(C) 2021. The Author(s).

This is an open access article published by Thieme under the terms of the Creative Commons Attribution-NonDerivative-NonCommercial-License, permitting copying and reproduction so long as the original work is given appropriate credit. Contents may not be used for commercial purposes, or adapted, remixed, transformed or built upon. (https://creativecommons.org/ licenses/by-nc-nd/4.0/)

Thieme Medical Publishers, Inc., 333 Seventh Avenue, 18th Floor, New York, NY 10001, USA
} 
Conclusion Ophthalmology residency program directors recognized the importance of an ethics and professionalism curriculum. However, there was marked variation in teaching and assessment methods. Additional work is necessary to identify optimal strategies for teaching and assessing competence in these areas. In addition, a substantial number of trainees were prohibited from graduating or required remediation due to ethics and professionalism issues, suggesting an impact of unethical and unprofessional behavior on resident attrition.

Ethics and professionalism are formal components of undergraduate medical education. ${ }^{1}$ Within ophthalmology, the American Academy of Ophthalmology (AAO), 2,3 American Board of Ophthalmology (ABO), ${ }^{4}$ and International Council of Ophthalmology (ICO $)^{5}$ have ethics and professionalism position statements and ethics committees, and offer educational activities in these areas, underscoring the profession's commitment to ethical practice and upholding the highest standards of professionalism.

Students may be at risk of an "ethical erosion," a deterioration or stagnation of ethical development, moral reasoning, and ethical sensitivity, as they progress through medical school $^{6-8}$ and begin clinical practice ${ }^{9}$; this can be exacerbated by a gap in dedicated teaching of ethics during residency. ${ }^{10-12}$ The Accreditation Council for Graduate Medical Education (ACGME) requires all accredited residency programs, including ophthalmology, to have didactic sessions in ethics, and professionalism is one of the six core competencies. $^{13}$ The remaining five core competencies (patient care, medical knowledge, practice-based learning and improvement, interpersonal and communication skills, and systemsbased practice) also indirectly address ethics-related aspects of medical practice (e.g., informed consent, shared decisionmaking, and respecting privacy). ${ }^{14}$

There is no consensus about what elements should be included in ethics and professionalism education during residency, ${ }^{15}$ how to assess competence, ${ }^{15}$ or how or when to remediate unethical or unprofessional behavior. ${ }^{16}$ There is literature that supports the value of a formal ethics and professionalism curriculum with defined benchmarks for surgery trainees. ${ }^{10,17,18}$ Educators have proposed using critical reflection, ${ }^{19}$ case studies, ${ }^{20}$ and models of emotional intelligence ${ }^{21}$ as techniques for developing and implementing a curriculum. Some programs incorporate didactic lectures and workshops on professionalism into their curriculum. However, these subjects are also taught through experiential learning and role-modeling, often referred to as the "hidden curriculum." 22 Unlike other core competencies, it is difficult to define ${ }^{17,18}$ and operationalize ${ }^{19}$ the concepts of ethics and professionalism, making it challenging to develop benchmarks and quantify proficiency. ${ }^{20}$

There is limited literature regarding ethics and professionalism curricula in residency programs. In a survey of pediatric residency program directors, over half of responding programs taught ethics without a structured curriculum. ${ }^{21}$ Obstetrics and gynecology residency program directors reported curricular crowding and lack of faculty expertise in ethics as barriers to implementing a curriculum. ${ }^{22}$ We sought to determine how ophthalmology residency programs comply with the ACGME's ethics and professionalism requirements. As awareness of physician burnout ${ }^{23}$ and its correlation with unprofessional behavior ${ }^{24}$ has grown, this is an area of increased interest among educators. ${ }^{25}$

We conducted a survey of ophthalmology residency program directors in the United States, investigating how programs teach and assess ethics and professionalism, and program-reported barriers to curriculum implementation. We also explored program directors' perceptions of trainee preparedness for independent practice in these areas.

\section{Methods}

\section{Creation of Survey}

Two of the authors (M.E.C. and J.E.D.-B.) developed an anonymous 17-question web-based survey, modeled from two previously published surveys (Supplementary Material; available in the online version). ${ }^{21,26}$ The survey included four sections as follows: (1) demographics and residency program information, (2) ethics and professionalism curriculum, (3) trainee preparation in ethics and professionalism, and (4) setting priorities for an ethics and professionalism curriculum. Given that ethics and professionalism have significant overlap, to the extent that the ACGME even defines professionalism using the word "ethical," 13 they were considered as 1 unit for the majority of survey questions. On some questions, respondents were invited to choose more than one option. The survey was piloted on a sample of clinician educators in ophthalmology and ethics to ensure appropriate survey readability. The Johns Hopkins University School of Medicine Institutional Review Board approved the study.

\section{Distribution of Survey}

We distributed the survey to program directors at the 119 ACGME accredited ophthalmology residency-training programs in the United States ${ }^{27}$ via the Association of University Professors of Ophthalmology e-mail list for program directors. An accompanying cover letter explained that the survey participation was voluntary and responses were anonymous. The cover letter instructed respondents to complete one survey per program, and we set the survey link to be accessible only once from each browser. We sent three email reminders after distribution. The survey portal stayed open from December 5, 2017 to January 26, 2018. 
Table 1 Demographic characteristics of responding programs $(n=55)$

\begin{tabular}{|l|l|}
\hline Demographic characteristics & No. (\%) \\
\hline Respondents' role in residency program & \\
\hline Residency program director & $38(69)$ \\
\hline $\begin{array}{l}\text { Associate/assistant residency } \\
\text { program director }\end{array}$ & $15(27)$ \\
\hline Other & $2(4)$ \\
\hline Program size & \\
\hline Small (6 or less) & $5(9)$ \\
\hline Medium (7-15) & $37(67)$ \\
\hline Large (16+) & $13(24)$ \\
\hline Program location ${ }^{\text {a }}$ & \\
\hline South Atlantic & $13(24)$ \\
\hline Pacific & $10(18)$ \\
\hline Middle Atlantic & $9(16)$ \\
\hline East North Central & $7(13)$ \\
\hline West South Central & $6(11)$ \\
\hline New England & $3(5)$ \\
\hline West North Central & $3(5)$ \\
\hline East South Central & $2(4)$ \\
\hline Mountain & $2(4)$ \\
\hline U.S. Territories & $0(0)$ \\
\hline
\end{tabular}

${ }^{a}$ South Atlantic (Delaware, Maryland, District of Columbia, Virginia, West Virginia, North Carolina, South Carolina, Georgia, Florida); Pacific (Washington, Oregon, California, Alaska, Hawaii); Middle Atlantic (New York, New Jersey, Pennsylvania); East North Central (Ohio, Indiana, Illinois, Michigan, Wisconsin); West South Central (Arkansas, Louisiana, Oklahoma, Texas); New England (Maine, New Hampshire, Vermont, Massachusetts, Rhode Island, Connecticut); West North Central (Minnesota, lowa, Missouri, North Dakota, South Dakota, Nebraska, Kansas); East South Central (Kentucky, Tennessee, Alabama, Mississippi); Mountain (Montana, Idaho, Wyoming, Colorado, New Mexico, Arizona, Utah, Nevada); U.S. Territories (Puerto Rico).

\section{Data Analysis}

Respondents self-identified in which of the 10 U.S. regions their program was located. For analyses, we categorized programs as small ( $\leq 6$ residents), medium (7-15 residents), and large ( $\geq 16$ residents). We categorized hours of ethics and professionalism education per year as $<5$ hours, 5 to 10 hours, and $>10$ hours. We presented descriptive data as numbers and proportions; we compared distributions of frequency in different groups using the Chisquare test, and hours of education in different groups using one-way analysis of variance (ANOVA). We performed all statistical analysis using STATA 14.0 (StataCorp., College Station, TX).

\section{Results}

Fifty-five respondents returned the survey for a response rate of $46 \%$ (55/119). Of them, $87 \%$ (48/55) completed the
Table 2 Strategies used by programs to teach ethics and professionalism $(n=53)$

\begin{tabular}{|l|l|}
\hline Teaching strategy & No. (\%) \\
\hline $\begin{array}{l}\text { Case-based discussions with } \\
\text { residents and facilitators }\end{array}$ & $34(64)$ \\
\hline Informal discussions & $29(55)$ \\
\hline Lectures/grand rounds by ethics faculty & $21(40)$ \\
\hline Behavior modeling & $19(36)$ \\
\hline $\begin{array}{l}\text { Lectures/grand rounds by } \\
\text { ophthalmology faculty }\end{array}$ & $18(34)$ \\
\hline Online teaching modules & $17(32)$ \\
\hline Assigned readings & $6(11)$ \\
\hline Ethics sessions offered by AAO & $4(8)$ \\
\hline Other & \\
\hline Ethics committee meetings & $4(8)$ \\
\hline Conferences with social work/pastoral care & $2(4)$ \\
\hline Ethics sessions at ophthalmology meetings & $2(4)$ \\
\hline Simulation laboratory & $1(2)$ \\
\hline Panel discussions & $0(0)$ \\
\hline Hospital legal/risk management seminars & $0(0)$ \\
\hline Hospital IRB meetings & $0(0)$ \\
\hline
\end{tabular}

Abbreviations: AAO, American Academy of Ophthalmology; IRB, institutional review board.

aSurvey participants were able to select multiple responses.

bIncludes nonmedical literature reading and discussion, book club, and a longitudinal course curriculum.

entire survey, while $13 \%$ (7/55) did not answer one or more questions on the survey.

\section{Demographics and Residency Program Information}

Ninety-six percent $(53 / 55)$ of respondents were residency program directors $(38 / 55,69 \%)$ or associate/assistant residency program directors $(15 / 55,27 \%)$. Of the two respondents who were neither program directors nor assistant program directors, one reported that they were a former program director and one did not disclose their role. The median program size was 12 (range: 3-24) residents. The proportion of respondents and nonrespondents did not differ by region ( - Table $\mathbf{1})$.

\section{Ethics and Professionalism Curriculum}

The mean number of hours spent annually teaching an ethics and professionalism curriculum was $6.3 \pm 3.8$ (range: 2 -$15)$ hours. Ten percent of respondents $(5 / 48)$ reported to spend 2 hours and $8 \%(4 / 48)$ spent 15 or more hours. The number of hours spent teaching ethics and professionalism topics did not differ by residency program size. Most of the programs (34/49,69\%) had a core set of ethics and professionalism teaching topics. However, some selected topics based on current issues of interest in the news (24/49, 49\%) or resident and faculty input regarding issues that arose during patient encounters $(26 / 49,53 \%)$. The three most 
Table 3 Topics included in programs' ethics and professionalism teaching $(n=49)$

\begin{tabular}{|l|l|}
\hline Ethics topic & No. (\%) \\
\hline Informed consent & $38(78)$ \\
\hline Disclosing medical errors & $37(76)$ \\
\hline Conflict of interest & $33(67)$ \\
\hline Protecting patient confidentiality & $32(65)$ \\
\hline Communicating bad news & $30(61)$ \\
\hline Managing difficult patients & $30(61)$ \\
\hline $\begin{array}{l}\text { Medical research and human subjects } \\
\text { protection }\end{array}$ & $27(55)$ \\
\hline $\begin{array}{l}\text { Disclosure of trainee participation } \\
\text { in patient care }\end{array}$ & $22(45)$ \\
\hline Patient competence & $21(43)$ \\
\hline Allocation of health care resources & $14(29)$ \\
\hline Medical neglect/abuse & $11(22)$ \\
\hline Other ${ }^{\text {b }}$ & $8(16)$ \\
\hline Professionalism topic & $38(78)$ \\
\hline Risk management and litigation & $36(73)$ \\
\hline $\begin{array}{l}\text { Sensitivity and responsiveness } \\
\text { to a diverse patient population }\end{array}$ & $35(71)$ \\
\hline Physician impairment & $35(71)$ \\
\hline Medical record documentation & $30(61)$ \\
\hline Trainee well being & $1(2)$ \\
\hline Responsible use of social media & \\
\hline $\begin{array}{l}\text { Verbal or physical abuse or } \\
\text { sexual harassment }\end{array}$ & \\
\hline Other & \\
\hline & $35)$ \\
\hline
\end{tabular}

a Survey participants were able to select multiple responses.

bIncludes interpersonal relationships, management of

homeless/mentally ill patients, medicolegal issues, and professionalism in interdepartmental teams.

Includes programs that indicated they had no set topics.

common teaching strategies were case-based discussions (34/53, 64\%), informal discussions between faculty and residents based on patient encounters (29/53, 55\%), and lectures/grand rounds taught by ethics faculty $(21 / 53$, 40\%; - Table 2). The most common ethics topics taught were informed consent (38/49,78\%), disclosing medical errors (37/49, 76\%), and conflict of interest (33/49, 67\%; - Table 3); the most common professionalism topics taught were risk management and litigation (38/49, 78\%), sensitivity and responsiveness to a diverse patient population (36/49, 73\%), physician impairment (35/49, 71\%), medical record documentation (35/49, 71\%), and/or trainee wellbeing (35/49, 71\%; - Table 3).

\section{Trainee Preparation in Ethics and Professionalism}

To assess trainee competence, the majority of programs used 360 -degree global evaluation ${ }^{28}(36 / 48,75 \%)$, observation of a resident during an actual patient encounter (30/48, 63\%), and/or a resident portfolio $(26 / 48,54 \%)$, an organized collec-
Table 4 Strategies used to assess ethics and professionalism and level of preparation in these areas $(n=48)$

\begin{tabular}{|l|l|}
\hline Assessment strategy & No. (\%) \\
\hline 360-degree global evaluation & $36(75)$ \\
\hline Observation during actual patient encounter & $30(63)$ \\
\hline Resident portfolio & $26(54)$ \\
\hline Chart review & $6(13)$ \\
\hline $\begin{array}{l}\text { Observation during standardized } \\
\text { patient encounter }\end{array}$ & $5(10)$ \\
\hline Not applicable (no formal assessment done) & $5(10)$ \\
\hline Written examination & $1(2)$ \\
\hline OCEX & $0(0)$ \\
\hline $\begin{array}{l}\text { Supervisor observation of clinical } \\
\text { encounter with a patient }\end{array}$ & $0(0)$ \\
\hline Level of preparation & $31(65)$ \\
\hline Well prepared & $15(31)$ \\
\hline Very well prepared & $1(2)$ \\
\hline Minimally prepared & $1(2)$ \\
\hline Other & $0(0)$ \\
\hline Not prepared at all & \\
\hline
\end{tabular}

Abbreviations: OCEX, ophthalmic clinical evaluation exercise. ${ }^{\text {aS }}$ Urvey participants were able to select multiple responses. bincludes a program that indicated they do not have good metrics to assess preparation.

Table 5 Barriers to development, implementation and maintenance of an ethics and professionalism curriculum $(n=48)$

\begin{tabular}{|l|l|}
\hline Barrier & No. (\%) \\
\hline Lack of faculty expertise/formal training & $25(52)$ \\
\hline Lack of time in resident teaching curriculum & $24(50)$ \\
\hline Lack of faculty time to develop a curriculum & $24(50)$ \\
\hline Lack of faculty time to teach a curriculum & $14(30)$ \\
\hline No barriers identified & $12(25)$ \\
\hline Lack of trainee interest & $10(21)$ \\
\hline $\begin{array}{l}\text { Lack of departmental leadership support } \\
\text { to develop a curriculum }\end{array}$ & $5(10)$ \\
\hline Lack of administrative support & $5(10)$ \\
\hline Other & $0(0)$ \\
\hline
\end{tabular}

aSurvey participants were able to select multiple responses.

tion documenting a resident's work, evaluations, and achievements. Ten percent of respondents (5/48) did not report use of a formal assessment to evaluate trainee competence (-Table 4 ).

Ninety-five percent of respondents (46/48) reported, in the past 5 years, their trainees were well prepared $(31 / 48$, $65 \%)$ or very well prepared $(15 / 48,31 \%)$ at the time of graduation in the areas of ethics and professionalism (-Table 4). Trainees' readiness did not differ by program size or hours spent teaching ethics and professionalism. 
Thirteen percent of respondents (6/48) reported that, within the past 5 years, their program had prohibited a trainee from graduating due to unethical or unprofessional conduct. An additional 19\% (9/48) reported having required trainee remediation prior to allowing them to graduate. There was no correlation between hours spent on ethics education or size of the residency program and prohibition from graduating or requirements for remediation. One respondent $(1 / 48,2 \%)$ reported declining to attest to a resident's good standing to sit for the $\mathrm{ABO}$ qualifying examinations, and two respondents $(2 / 48,4 \%)$ declined to attest to a resident's good standing on a credentialing verification form. All respondents who reported declining to attest to a resident's good standing for the $\mathrm{ABO}$ qualifying examinations and/or credentialing verification also reported prohibiting a trainee from graduating due to unethical or unprofessional conduct.

\section{Setting Priorities for an Ethics and Professionalism Curriculum}

Nearly all respondents ( $47 / 48,98 \%$ ) felt it was very important $(33 / 48,69 \%)$ or moderately important $(14 / 48,29 \%)$ that their program dedicate curricular time to teaching ethics and professionalism. Thirty-three percent (16/48) reported that the time spent teaching these topics was too little. The most common barriers identified to developing, implementing, and maintaining an ethics and professionalism curriculum were lack of faculty expertise/formal training in teaching ethics and professionalism (25/48,52\%) and lack of time in the resident didactics schedule (24/48, 50\%; - Table 5).

\section{Discussion}

There is limited published data about ethics and professionalism curricula for ophthalmology residents or trainee preparedness in these areas. This study is a step toward understanding the current state of ethics and professionalism education and opportunities to enhance curriculum and assessment measures. Respondents reflected a wide range of program locations and sizes. The survey response rate was commensurate with other studies of residency program directors. ${ }^{11,22,29,30}$

Results show that there is marked variation in how ethics and professionalism are taught and assessed in U.S. ophthalmology residency programs. Even the most frequently identified topics were taught by fewer than $80 \%$ of responding programs, and less than half of respondents reported formally covering disclosure of trainee participation in patient care or verbal/physical abuse or sexual harassment. Although it is likely that conversations around all of these topics are taking place informally in most, if not all, of the residency programs, there is a notable lack of consistency.

Overall 1 in 10 respondents did not employ formal assessment of trainee preparedness in ethics and professionalism, underscoring a lack of consensus on how to accurately evaluate residents in these areas. For programs using a formal assessment, methods identified align with those most frequently used in the ACGME's Ophthalmology Milestone Project. ${ }^{14}$ However, no respondents reported using the Ophthalmic
Clinical Evaluation Exercise (OCEX) which the ACGME recommends as an assessment tool for each professionalism competency milestone. ${ }^{14}$ Given the apprenticeship model of medical education, ${ }^{31-33}$ there is inevitably variation in teaching and assessment techniques; this is not inherently problematic nor is it unique to ethics and professionalism.

Another, perhaps more troubling, finding was that almost one-third of responding programs reported prohibiting a trainee from graduating or required remediation due to unethical or unprofessional behavior. One previous study reported $12 \%$ of 121 residents were asked to leave their residency program due to surgical competence concerns. ${ }^{34}$ In addition, the ACGME reports that during the 2018 to 2019 academic year, $11.1 \%$ of the total 2,161 U.S. residents who left their programs prior to graduation did so because they had either been dismissed or unsuccessfully completed their program. ${ }^{35}$ While there is no public database available on resident attrition due to ethics and professionalism concerns specifically, and although our survey did not ask specific questions about the behavior issues identified nor remediation strategies used, this rate of termination and remediation is concerning and speaks to the potential impact of unethical and unprofessional behavior on resident attrition.

There is discordance between our finding that one-third of programs cited an ethical or professional behavior issue that impacted graduation, while the vast majority felt their residents were well or very well prepared in these areas. The perceived level of preparation is consistent with the results of a survey which found that over three quarters of young ophthalmologists felt their residency programs had prepared them very well or extremely well to practice professionalism. ${ }^{36}$ Perhaps respondents to our survey felt that their programs had effectively identified trainees who required intervention or perceived terminated residents as outliers. However, this discordance may underscore limitations in knowing how to assess competence in ethics and professionalism.

There is also a discordance between our findings that $31 \%$ of respondents either prohibited a resident from graduating or required remediation prior to graduating, while only 4 and $2 \%$ declined to attest to a resident's good standing on a credentialing verification form or to sit for an $\mathrm{ABO}$ qualifying examination due to unethical or unprofessional conduct, respectively. It is possible that the students who were prohibited from graduating were asked to leave their programs before they had reached the point of credentialing. It is also possible that those who were asked to remediate either did so successfully, such that programs felt comfortable attesting to their good standing or are recent graduates who have not yet reached the point of credentialing. Future research is needed to fully understand the reasons for this concerning finding.

While there was significant variation among programs regarding the amount of time spent teaching ethics and professionalism, there was no correlation between a program's hours spent teaching an ethics or professionalism curriculum and likelihood of prohibiting a trainee from graduating. This suggests that setting a requirement for number of hours in the trainee curriculum alone may not be sufficient. It is also important to prioritize topics, identify 
effective teaching methods, and define tools and benchmarks for assessment. Existing benchmarks include three ethicsand professionalism-related scales laid out by the ACGME's Ophthalmology Milestones project which allows the Clinical Competency Committee to assess trainees' competence in professional behavior and ethical principles, accountability and conscientiousness, and self-awareness and help-seeking on a 1-to-5 scale. ${ }^{14}$ Other practices that ophthalmology residency programs may consider adapting include Likert's scale quantitative evaluations, peer-based evaluations, and feedback based on case-based workshops. ${ }^{37,38}$

Since lack of time in the resident didactics schedule is a leading barrier, educators must be cognizant of competing time demands and identify strategies to integrate ethics and professionalism topics into existing teaching material. A lack of faculty expertise in teaching ethics and professionalism was another leading barrier, and although lack of faculty time was identified as a barrier, it ranked considerably lower. This suggests that faculty may be willing to teach if a structured curriculum and sufficient training that accounted for their competing time demands were available.

We do not know if teaching an ethics and professionalism curriculum would have prevented the trainee termination and probation events that respondents reported. This is not a new debate. ${ }^{39}$ In 2002, the Archives of Ophthalmology published a point-counterpoint on teaching ethics, posing the question of whether ethics could be taught to ophthalmology residents. ${ }^{40,41}$ One author highlighted the value of an informal curriculum, ${ }^{41}$ where ethics should be "encouraged by discussion, humane example, and suggestion to examine one's behavior continually," while the other outlined the benefit of a structured curriculum. ${ }^{40}$ We believe that there is a need for both informal and structured elements to an ethics and professionalism curriculum. A formal curriculum may allow students to reinforce explicit ethical knowledge and reasoning skills, ${ }^{42}$ and standardized assessment tools would allow for systematic comparison of teaching strategies to determine the most effective methods. ${ }^{7}$ An informal curriculum supports frequent discussion of ethical issues raised during clinical encounters and embraces the concept of everyday ethics in which ethics and professionalism issues are recognized as inherent in daily patient and physician encounters. $^{43}$ Programs could incorporate regular conversations about ethics and professionalism by using strategies like the 1-minute preceptor model to incorporate brief structured teaching into busy clinic settings. ${ }^{44}$ Similarly, Larkin et al argue for a skill-based framework to foster a culture of virtue among trainees. Their framework utilizes both a formal and informal curriculum, enabling trainees to both recognize and manage ethical dilemmas in patient care. ${ }^{45}$

It may be possible to mitigate adverse outcomes such as resident remediation or termination due to unethical or unprofessional behavior by developing a comprehensive approach to ethics and professionalism education and training faculty in this area. More research is necessary to understand the relationship between ethics and professionalism education and misconduct and identify optimal strategies for teaching and assessing competence in these areas.

\section{Limitations}

This study has some limitations. Given the varying definitions of ethics and professionalism, ${ }^{17,18}$ there may have been confusion in what was meant by certain terms. The survey was not validated prior to distribution, and there is a lack of information about the $54 \%$ of U.S. ophthalmology residency programs that did not respond. A reluctance to answer questions about remediation or termination may have impacted survey participation. Although we invited one response per program, more than one person may have responded. While distribution of responses was consistent with programs' geographic distribution, the anonymous nature of the survey prohibited exploration of other potential differences between programs that responded and those that did not. Associate or assistant program directors, who constituted almost one-third of respondents, may have a different level of knowledge about the curriculum than program directors. Respondents also may not be directly responsible for developing or teaching their program's ethics and professionalism curriculum, and their knowledge may be incomplete. Similarly, we did not ask respondents to report the length of time they have spent working in resident education which may have provided more insight into their experience surrounding resident ethics and professionalism issues. Furthermore, while our survey focused on formal aspects of the ethics and professionalism curricula, our results may not capture the entirety of a program's curriculum or the "hidden" curriculum which plays a substantial role in shaping trainees' attitudes and behaviors.

\section{Conclusion}

While ophthalmology residency program directors recognize the importance of an ethics and professionalism curriculum, there is marked variation in topics taught and assessment method, and a substantial number of trainees were prohibited from graduating or required remediation due to ethics and professionalism issues. Further work should identify optimal strategies for teaching ethics and professionalism and assessing competence in these areas and examine the utility of a formal or structured curriculum. Furthermore, since a significant barrier to implementing a structured curriculum was lack of faculty expertise, faculty must be given the appropriate skills and resources to teach an ethics and professionalism curriculum. Further research should also be done to study the feasibility, utility, and impact of various methods for teaching and assessing competence in the areas of professionalism and ethical behavior among residents.

Funding

The authors report no external funding source for this study.

\section{Conflicts of Interest}

M.V.B. reports personal fees from Carl Zeiss Meditec, outside the submitted work. 


\section{References}

1 Lehmann LS, Kasoff WS, Koch P, Federman DD. A survey of medical ethics education at U.S. and Canadian medical schools. Acad Med 2004;79(07):682-689

2 American Academy of Ophthalmology. Code of ethics. Accessed January 12, 2018 at: https://www.aao.org/ethics-detail/code-ofethics

3 American Academy of Ophthalmology. Ethics and the academy. Accessed January 29, 2018 at: https://www.aao.org/about/ethics

4 American Board of Ophthalmology Board Certification Guidelines. Accessed January 29, 2019 at: https://abop.org/maintaincertification/

5 Ethical Guidelines for Ophthalmologists: Ethical Principles and Professional Standards.

6 Feudtner C, Christakis DA, Christakis NA. Do clinical clerks suffer ethical erosion? Students' perceptions of their ethical environment and personal development. Acad Med 1994;69(08):670-679

7 Eckles RE, Meslin EM, Gaffney M, Helft PR. Medical ethics education: where are we? Where should we be going? A review. Acad Med 2005;80(12):1143-1152

8 Hojat M, Shannon SC, DeSantis J, Speicher MR, Bragan L, Calabrese LH. Does empathy decline in the clinical phase of medical education? a nationwide, multi-institutional, cross-sectional study of students at DO-granting medical schools. Acad Med 2020;95(06):911-918

9 Stratta EC, Riding DM, Baker P. Ethical erosion in newly qualified doctors: perceptions of empathy decline. Int J Med Educ 2016; 7:286-292

10 Helft PR, Eckles RE, Torbeck L. Ethics education in surgical residency programs: a review of the literature. J Surg Educ 2009;66(01):35-42

11 Plauth WH III, Pantilat SZ, Wachter RM, Fenton CL. Hospitalists' perceptions of their residency training needs: results of a national survey. Am J Med 2001;111(03):247-254

12 Carrese JA, McDonald EL, Moon M, et al. Everyday ethics in internal medicine resident clinic: an opportunity to teach. Med Educ 2011;45(07):712-721

13 ACGME program requirements for graduate medical education in ophthalmology. Accessed January 29, 2018 at: http://www. icoph.org/downloads/ACGMEophthalmology.pdf

14 ACGME. The ophthalmology milestone project. Accessed June 7, 2018 at: http://www.acgme.org/Portals/0/PDFs/Milestones/OphthalmologyMilestones.pdf?ver=2015-12-09-125052-160

15 Lee AG, Beaver HA, Boldt HC, et al. Teaching and assessing professionalism in ophthalmology residency training programs. Surv Ophthalmol 2007;52(03):300-314

16 Adams KE, Emmons S, Romm J. How resident unprofessional behavior is identified and managed: a program director survey. Am J Obstet Gynecol 2008;198(06):692.e1-692.e4, discussion 692.e4-692.e5

17 Swick HM. Toward a normative definition of medical professionalism. Acad Med 2000;75(06):612-616

18 Birden H, Glass N, Wilson I, Harrison M, Usherwood T, Nass D. Defining professionalism in medical education: a systematic review. Med Teach 2014;36(01):47-61

19 Nichols BG, Nichols LM, Poetker DM, Stadler ME. Operationalizing professionalism: a meaningful and practical integration for resident education. Laryngoscope 2014;124(01):110-115

20 Hafferty FW, Franks R. The hidden curriculum, ethics teaching, and the structure of medical education. Acad Med 1994;69(11): 861-871

21 Cook AF, Sobotka SA, Ross LF. Teaching and assessment of ethics and professionalism: a survey of pediatric program directors. Acad Pediatr 2013;13(06):570-576

22 Byrne J, Straub H, DiGiovanni L, Chor J. Evaluation of ethics education in obstetrics and gynecology residency programs. Am J Obstet Gynecol 2015;212(03):397.e1-397.e8
23 Rotenstein LS, Torre M, Ramos MA, et al. Prevalence of burnout among physicians: a systematic review. JAMA 2018;320(11): 1131-1150

24 Dyrbye LN, West CP, Hunderfund AL, et al. Relationship between burnout, professional behaviors, and cost-conscious attitudes among US physicians. J Gen Intern Med 2020;35(05):1465-1476

25 Dyrbye LN, Massie FS Jr, Eacker A, et al. Relationship between burnout and professional conduct and attitudes among US medical students. JAMA 2010;304(11):1173-1180

26 Lang CW, Smith PJ, Ross LF. Ethics and professionalism in the pediatric curriculum: a survey of pediatric program directors. Pediatrics 2009;124(04):1143-1151

27 Accreditation Council for Graduate Medical Education: Advanced Program Search. Accessed July 27, 2018 at: https://apps.acgme.org/ads/Public/Programs/Search?stateId=\&specialtyId=41\&specialtyCategoryTypeId=\&numCode $=\&$ city $=$

28 Lockyer J. Multisource feedback in the assessment of physician competencies. J Contin Educ Health Prof 2003;23(01):4-12

29 Shah DN, Volpe NJ, Abbuhl SB, Pietrobon R, Shah A. Gender characteristics among academic ophthalmology leadership, faculty, and residents: results from a cross-sectional survey. Ophthalmic Epidemiol 2010;17(01):1-6

30 Scott IU, Smalley AD, Kunselman AR. Ophthalmology residency program leadership expectations of resident competency in retinal procedures and resident experience with retinal procedures. Retina 2009;29(02):251-256

31 Dornan T. Osler, Flexner, apprenticeship and 'the new medical education'. J R Soc Med 2005;98(03):91-95

32 Marckmann G. Teaching science vs. the apprentice model del al education." ship expectat. Med Health Care Philos 2001;4(01): 85-89

33 Munson R. Why medicine cannot be a science. J Med Philos 1981; 6(02):183-208

34 Binenbaum G, Volpe NJ. Ophthalmology resident surgical competency: a national survey. Ophthalmology 2006;113(07):1237-1244

35 ACGME Data Resource Book 2019-2020. Accessed December 30 2020 at: https://www.acgme.org/Portals/0/PFAssets/PublicationsBooks/2019-2020_ACGME_DATABOOK_DOCUMENT.pdf

36 McDonnell PJ, Kirwan TJ, Brinton GS, et al. Perceptions of recent ophthalmology residency graduates regarding preparation for practice. Ophthalmology 2007;114(02):387-391

37 Nittur N, Kibble J. Current practices in assessing professionalism in United States and Canadian allopathic medical students and residents. Cureus 2017;9(05):e1267

38 Malakoff GL, Payne CL, Staton LJ, Kolade VO, Panda M. Accounting for professionalism: an innovative point system to assess resident professionalism. J Community Hosp Intern Med Perspect 2014;4 (02):23313

39 Siegler M. Training doctors for professionalism: some lessons from teaching clinical medical ethics. Mt Sinai J Med 2002;69 (06):404-409

40 Day SH. A structured curriculum on ethics for ophthalmology residents is valuable. Arch Ophthalmol 2002;120(07):963-964

41 Smith ME. A structured curriculum on ethics for ophthalmology residents is not valuable. Arch Ophthalmol 2002;120(07):965

42 Brewster LP, Hall DE, Joehl RJ. Assessing residents in surgical ethics: we do it a lot; we only know a little. J Surg Res 2011;171 (02):395-398

43 Dugdale LS, Siegler M, Rubin DT. Medical professionalism and the doctor-patient relationship. Perspect Biol Med 2008;51(04): 547-553

44 Neher JO, Gordon KC, Meyer B, Stevens N. A five-step tep and the doctor-patient relationship. J Am Board Fam Pract 1992;5(04): 419-424

45 Larkin GL, McKay MP, Angelos P. Six core competencies and seven deadly sins: a virtues-based approach to the new guidelines for graduate medical education. Surgery 2005;138(03):490-497 